\title{
Cidades médias e atração de migrantes qualificados
}

\author{
Adriana Mota Barbosa* \\ Ralfo Edmundo da Silva Matos** \\ Carlos Fernando Ferreira Lobo ${ }^{* * *}$
}

\section{Resumo}

A reflexão e pesquisa investigam como o Estado tem atuado no território enquanto fomentador de políticas de formação, qualificação e requalificação da força de trabalho e discutem as relações que se estabelecem com o desenvolvimento econômico e demográfico. O estudo resgata as metamorfoses do conceito de cidade média e o papel da migração no dinamismo econômico e demográfico destas localidades. Com o respaldo da pesquisa bibliográfica e em consonância com a metodologia adotada, foram selecionados os municípios mineiros de porte médio, com sede de Instituto Federal e crescimento demográfico e da renda no período de 2000 a 2010 e feitas comparações com os demais municípios, de mesmo porte que não possuem um Instituto Federal. A averiguação empírica é confrontada com o referencial teórico construído a fim de inferir a validade da hipótese levantada e as conclusões gerais atestam a comprovação da mesma.

Palavras-chave: Cidades médias; Desenvolvimento; Educação; Migração.

** Professora da Universidade Federal de Juiz de Fora (adriana.mota@ufjf.edu.br).

**** Professor do Istituto de Geociências da UFMG (ralfo@igc.ufmg.br).

******Professor do Instituto de Geociências da UFMG (cfflobo@yahoo.com.br).

Geosul, Florianópolis, v. 30, n. 60, p 69-88, jul./dez. 2015 
BARBOSA, A.M. et al. Cidades médias e atração de migrantes qualificados.

\title{
Medium cities and attraction of skilled migrants
}

\begin{abstract}
The reflection and the research investigate how the State has been acting in the territory as a developer of training policies, qualifying the workforce; they discuss the relations established between economic and demographic development. The study rescues the metamorphosis of the concept of average city and the role of migration on the economic and demographic dynamism of those places. Backed by the research literature and in line with the methodology adopted, the medium-size cities of Minas Gerais that have a Federal Institute and demographic and income growth in the period of 2000 to 2010 were selected. Comparisons were made with municipalities of the same size that do not have the institution. The empirical research is confronted with the theoretical framework constructed to infer the validity of the hypothesis and the general findings prove it.
\end{abstract}

Key words: Medium cities; Development; Education; Migration.

\section{Introdução}

As interfaces entre rede urbana e migrações internas são o objeto central desse artigo, vis-à-vis os impactos locacionais dos IFETs (Institutos Federais de Educação Profissional e Tecnológica) em cidades médias de Minas Gerais. O pressuposto é que os IFETs inserem-se no processo de interiorização da urbanização no Brasil recente, ao lado da dispersão relativa da força de trabalho e da atividade econômica.

Inicialmente, são discutidas as dificuldades de conceituar as cidades médias e, a seguir, apresentadas as interfaces entre rede urbana e cidades médias dinâmicas, o que significa atratividade de população e crescimento da renda. O papel das migrações recebe destaque na terceira parte do artigo. A presença do IFET no município é o balizador de comparação entre os municípios 
BARBOSA, A.M. et al. Cidades médias e atração de migrantes qualificados.

mineiros selecionados e os achados desse exercício empírico sedimentam as conclusões do artigo.

\section{As cidades médias em perspectiva}

Cidade média não é apenas um estoque de população de certo tamanho, mas supõe considerar seu papel na hierarquia da rede cidades e sua importância regional. Um recurso analítico pode ser distinguir cidade "média" de cidade "intermédia", atribuindo a primeira a faceta estática, o peso de sua população e à última, elementos dinâmicos, noção estratégica de espaço a conquistar, de posicionamento a ocupar, de desenvolvimento de sinergias e de mediações entre os homens e capitais (GAULT, 1989), de tal forma a compor um tipo específico de cidade dinâmica de porte médio.

As cidades intermédias são dotadas de melhores equipamentos e serviços de educação, saúde, cultura e comércio, constituindo-se locais privilegiados para novos investimentos, inclusive os de origem internacional. Além disso, possuem uma capacidade de integração em redes que pode suplantar o âmbito nacional, convertendo-se assim, em cidades significativamente dinâmicas, em termos econômicos e demográficos. Disso pode ser inferido que a oferta de serviços educacionais, principalmente os que são públicos, gratuitos e diversificados são fatores de atração populacional para os municípios onde se instalam.

$\mathrm{O}$ adjetivo intermédia/intermediária introduz a esse tipo de estudo dimensões que extrapolam os atributos meramente demográficos e de extensão territorial. Sanfeliu e Torné (2004) destacam que os desafios para o entendimento da cidade intermediária repousam, sobretudo, na necessidade de tomá-la enquanto geradora de relações que substituem o aspecto estático e hierarquizado das teorias clássicas de sistema urbano por uma concepção mais aberta, dinâmica e interativa. Desta forma, a cidade intermediária estabelece a ligação entre os níveis superiores e inferiores da hierarquia. Além disso, é a ponte com outras cidades intermédias de funções idênticas ou complementares, no território 
BARBOSA, A.M. et al. Cidades médias e atração de migrantes qualificados.

nacional ou internacional, articulando-se em rede, "[...] numa visão de integração num espaço mais abrangente" (MARQUES DA COSTA, 2002, p. 117).

Diversos predicados apoiam a acepção de cidade intermediária, sobretudo, sua capacidade de: (i) fornecer bens e serviços mais ou menos especializados para sua população e para populações vizinhas, sobre as quais exerce certa influência; (ii) atuar como um centro de interação social, econômica e cultural; (iii) operar como nós que articulam fluxos, pontos de referência e acesso a outros níveis da rede; (iv) abrigar níveis de administração do governo local e regional através dos quais canalizam as demandas populacionais (SANFELIU e TORNE, 2004, p. 7).

Embasada na distinção entre cidade média e intermédia, Nubis Pulido (1999) apresenta uma tipologia das cidades médias venezuelanas, passíveis de serem classificadas como intermédias, a partir de três parâmetros que a autora considerou essenciais: a capacidade de intercâmbio, a autonomia financeira e política e o potencial de liderança. Tais fatores foram medidos por uma série de variáveis e sub-variáveis, qualitativas e quantitativas, ao longo dos anos 90 que, submetidas ao tratamento estatístico, permitiram criar um "índice de intermédia". Na composição deste índice, o potencial de liderança no espaço representou $25 \%$ e foi medido pela relevância da atividade industrial na cidade (número de empregos, importância relativa do parque industrial no conjunto regional e investimentos) e seu potencial em relação à educação superior e à pesquisa, abrangendo, neste caso, além de universidades, institutos e colégios. Indústria e educação dividiram igualmente o percentual de peso na composição do índice.

Especificamente, a capacidade de liderança da cidade intermédia é descrita por Pulido (2006, p. 159) como sendo o potencial de polarização no espaço através da presença de atividades chave, tais como a indústria, a pesquisa e o ensino superior que além de simbolizarem sua inserção na sociedade moderna, imprimem também um "[...] poder económico cultural y 
BARBOSA, A.M. et al. Cidades médias e atração de migrantes qualificados.

político adicional que se traduciría, em el nivel espacial, por una más vasta influencia territorial"1.

A transposição de status de cidade média para intermediária na rede global pressupõe, segundo Sanfeliu e Torné (2004, p. 9-10) mais do que uma posição de destaque na conexão com as grandes redes e fluxos. A cidade intermediária deve apresentar uma vocação criativa e de adaptação às inovações, estratégias de especialização competitiva, competência para aproveitar os recursos endógenos próprios de seu território, de modo a favorecer também a identidade sociocultural do meio urbano e territorial e ampliar a coesão social, a cooperação e o voluntariado dos principais agentes sociais da cidade. Ou seja, implica o desejo de levar adiante um "projeto" de cidade, a partir da gestão institucional local, do meio e de seus recursos, comprometida com a melhoria de sua condição física e ambiental e com a garantia de qualidade de vida para toda a população. Para tanto, os autores enfatizam a "[...] atención que se de a la educación, preparación y calificación de sus ciudadanos"2 (SANFELIU e TORNÉ, 2004, p.9).

$\mathrm{Na}$ avaliação de Amorim Filho e Abreu (2002, p.7), a cidade média vincula-se ao conceito de tecnópole cujos atributos principais são a capacidade de criação, reciclagem e difusão de inovações científicas, sobretudo tecnológicas. Pressupõe um ambiente de boa qualidade de vida, um sistema de comunicações e informática eficientes e indústrias que apliquem as inovações tecnopolitanas. Os autores, no caso específico de Minas Gerais, criaram uma metodologia de hierarquização de 102 cidades médias a partir de seu potencial para criação e/ou desenvolvimento de um polo tecnológico. As cidades de Juiz de Fora e Uberlândia ocuparam o nível superior da hierarquia e apresentaram características muito semelhantes: população em torno de 500 mil

1 [...] poder econômico, cultural e político adicional que se traduziria no nível espacial, por uma maior influência territorial (Tradução nossa).

2 [...] a atenção que se dê à educação, preparação e qualificação dos seus cidadãos (Tradução nossa). 
BARBOSA, A.M. et al. Cidades médias e atração de migrantes qualificados.

habitantes; equipamentos de infraestrutura básica além de ligações aeroviárias, rodoviárias e de telecomunicações bastante satisfatórias; qualidade de vida, Índice de Desenvolvimento Humano (IDH) e Renda Familiar entre os mais altos do estado; parque industrial dinâmico e um robusto sistema educacional com cursos e laboratórios de nível tecnopolitano. Nesse mesmo trabalho, comparecem com alta centralidade na hierarquia de potencial tecnológico Pouso Alegre, Poços de Caldas, Governador Valadares e Montes Claros, cidades que receberam um IFET até o final de 2011. Nestas localidades, o IFET parece ter tido a função de potencializar sinergias já existentes na cidade e/ou região, de modo a consolidar a associação cidade média dinâmica e IFET.

As conclusões de Amorim Filho e Abreu (2002) convergem com a trajetória proposta por Sanfeliu e Torné (2004) que afirmam que dinamismo é mais do que um esforço solitário de cada localidade porquanto expande as potencialidades para outras cidades intermediárias da rede, ao estabelecerem relações de complementaridade e cooperação.

Em certa medida, a aplicação dos propósitos do Instituto Federal de Educação, Ciência e Tecnologia no Brasil pode significar catalisação de processos de consolidação da urbanização interiorizada, nos moldes da proposta de Sanfeliu e Torné (2004), sobretudo, se esses equipamentos se instalem em cidades médias capazes de articular toda a vida de relações da região. Isso introduz processos de transformação que favorecem a consolidação de cidades médias dinâmicas.

\section{A rede urbana e as cidades médias dinâmicas}

A descompressão do crescimento urbano central favorecido pela desconcentração econômica e demográfica nas últimas três décadas tem como resultante "[...] um Brasil mais integrado, amplamente urbanizado em seu interior, mas com níveis de desigualdades regionais e sociais pouco alterados" (MATOS, 2010, p. 47). A despeito da expressiva redução da taxa de fecundidade no 
BARBOSA, A.M. et al. Cidades médias e atração de migrantes qualificados.

país, o que chama a atenção dos estudiosos é que a diminuição no ritmo de crescimento das principais metrópoles alimenta correntes migratórias procedentes dessas áreas e dá consistência a um processo de dispersão espacial da população e das atividades econômicas que se manifesta nas últimas décadas (DINIZ, C., 1993; LOBO, 2010; MATOS, 1995, 1995b).

Lobo (2009, p. 35-36) recorre a Matos para explicar o processo de mudanças estruturais de longa duração pelo qual passou o Brasil nas últimas décadas, marcado pelo espraiamento industrial, acompanhado de um adensamento do sistema urbano que estreitou os vínculos de dependência e complementaridade na rede urbana brasileira e fez surgir localizações alternativas para investimentos econômicos e para novos níveis de especialização, para além do perímetro Sul-Sudeste.

A reestruturação atual da rede urbana brasileira tem alguns pontos relevantes, destacados por Corrêa (2006), entre os quais: (i) maior complexidade funcional e diferenciação regional; (ii) maiores e mais diversificadas interações espaciais de longa e curta distância; (iii) novos padrões de redes mais complexas do que as dentríticas ou christallerianas; (iv) modernas formas de urbanização como os novos aglomerados, as megalópoles e os corredores urbanos.

Nesse contexto, a aceleração dos ritmos econômicos trazida pelas redes técnicas imprime diferenciações no espaço, fortalecimento de vantagens locacionais e diferenciação dos lugares em função de seu conteúdo. Trata-se de uma dinâmica heterogênea capaz de revelar por meio da rede urbana, "[...] uma efetiva integração de parte da população ao sistema social e, simultaneamente, uma menor integração, senão exclusão, de parcela importante da população" (CORRÊA, 2001, p. 104).

Esse processo expressa um quadro de heterogeneidade do território nacional que produz rebatimentos na estrutura urbana ao favorecer a formação de bolsões de atratividade e/ou repulsão, responsáveis por trajetórias migratórias diversas, já lembradas por Motta e Ajara (1999). 
BARBOSA, A.M. et al. Cidades médias e atração de migrantes qualificados.

Assim, é possível ponderar que a cidade intermédia ou intermediária se apresenta, praticamente, como uma cidade média dinâmica que encerra fluxos que estruturam redes geográficas, favorecidos pelo terciário moderno que prima pela oferta de serviços - não só pelos empregos em potencial -, os quais contribuem para a diversificação da oferta de objetos culturais, de saúde e de educação. A proliferação desse tipo de cidade interfere na rede urbana do país e delineia novas espacialidades. Nesse ambiente, as migrações internas são, simultaneamente, causa e consequência de processos socioespaciais.

\section{As migrações internas}

Como visto, cidades médias dinâmicas possuem atributos que favorecem a implantação de infraestruturas socioeconômicas e o desenvolvimento de polos tecnológicos capazes de atrair migrantes de grandes metrópoles que padecem das chamadas "deseconomias de aglomeração". As migrações internas passam a ser essenciais para a compreensão do dinamismo dessas cidades, uma vez que o crescimento vegetativo da população é um processo mais lento e regular do que as flutuações resultantes dos fluxos migratórios (AMORIM FILHO e RIGOTTI, 2002). As trocas migratórias tornam-se mais decisivas em momentos nos quais há declínio do crescimento vegetativo.

Assim, as migrações internas afetam o desenvolvimento do país e estão relacionadas às transformações econômicas em suas várias manifestações setoriais e espaciais. Esses movimentos populacionais atuam significativamente no processo de formação do mercado de trabalho, "por meio do qual a expansão capitalista explicita as adaptações e/ou rupturas com as estruturas sociais anteriores", reordena os espaços econômicos e produz concentração e desigualdades regionais (MATOS, 1995b, p.45).

Parte relevante dos investimentos teóricos sobre a contribuição das migrações considera-a "[...] como mobilidade estritamente vinculada à criação, expansão e articulação dos 
BARBOSA, A.M. et al. Cidades médias e atração de migrantes qualificados.

mercados de trabalho no país" (LOBO, 2010, p.125). Tais estudos, entretanto, investem de modo insuficiente no entendimento das causas mais profundas da migração ${ }^{3}$, ao não vinculá-las às necessidades estruturais do capitalismo. Ademais, os efeitos positivos da migração nas áreas de destino nem sempre são esquadrinhados. Afinal, no âmbito da oferta de mão-de-obra qualificada convém levar em conta determinados investimentos que o migrante empreende para que se habilite tecnicamente. Há, portanto, aspectos sociais e culturais que extrapolam questões meramente econômicas. Ou seja, espelham processos espaciais que "[...] aglutinam força de trabalho, pequenos capitais, informações e trocas de experiência, além de outras dimensões subjetivas alusivas à cultura, expectativas de sucesso, etc.” (MATOS, 2002, p.7).

Além disso, ao se abordar a questão da migração é preciso atentar aos seus determinantes, em dois níveis de análise: (i) de caráter macroeconômico, que considere as diferenças no desenvolvimento regional; (ii) de caráter microeconômico, que reflita sobre os investimentos necessários e benefícios repassados pelo migrante, além de analisar as características das regiões de origem e de destino dos migrantes e considerar os custos e riscos da migração (BASTOS, et al., 2010). Nesse sentido, outro aspecto que precisa ser destacado diz respeito, especificamente, às pessoas que tomam a decisão de migrar. Bastos, Freguglia e Procópio (2010, p. 3-4) destacam que "de acordo com Borjas (1994), Chiswick (1978) e De Hass (2008) na literatura internacional, e Santos Júnior et al. (2005) na literatura nacional, o migrante é considerado uma pessoa mais habilidosa, mais esforçada, mais determinada que o não-migrante".

${ }^{3} \mathrm{O}$ conceito é empregado neste texto conforme o preconizado por Carvalho e Rigotti (1998, p. 339-340) e corresponde aos movimentos realizados por indivíduos que geram mudanças permanentes de residências entre unidades espaciais pré-definidas, neste caso, municípios. Alguns autores chamam de "migração pendular" os deslocamentos diários entre municípios distintos por razões de trabalho ou estudo, Isso, por definição não é migração. 
BARBOSA, A.M. et al. Cidades médias e atração de migrantes qualificados.

A seletividade participa das consequências da migração ao longo do tempo. Se no passado havia processos de seletividade na origem da migração campo-cidade, mais recentemente há contracorrentes que impactam positivamente cidades e regiões historicamente expulsoras de população.

As conclusões da pesquisa de BASTOS et al. (2010) confirmam as teses de Martine (1992) e Matos (1995) e convergem para a hipótese inicial deste trabalho de que está ocorrendo uma interiorização demográfica e econômica seletiva no país. Os autores constataram que as regiões metropolitanas estão tendo uma perda relativa de importância tanto no aspecto populacional quanto em termos econômicos. Além disso, a redução dos cores metropolitanos, em termos populacionais, é demonstrada pelos fluxos emigratórios crescentemente mais expressivos para as cidades médias, se comparados aos fluxos contrários (em direção às metrópoles). Já no que tange aos aspectos econômicos, os resultados do estudo indicam que a migração provocou uma transferência de parte da renda das metrópoles para os demais níveis da hierarquia urbana.

BASTOS et al. (2010), especificamente, concluíram que a migração intermunicipal, no Brasil, ocorrida no período de 1995/2000 contribui para redução da desigualdade da renda do trabalho entre os indivíduos e também para a diminuição da desigualdade entre os níveis da hierarquia urbana brasileira. Salientam também a necessidade de que, nas formulações de políticas públicas voltadas para o decréscimo das disparidades regionais brasileiras, sejam consideradas, além das desigualdades entre os estados e as macrorregiões, as características dos níveis hierárquicos dos municípios brasileiros.

A parte empírica do trabalho de Ramos (2011) demonstrou, entre outros aspectos, que a Taxa Líquida de Migração (TLM) do quinquênio 1995-2000 de municípios mineiros de porte médio (entendidos, como os que possuíam no ano de 2000 entre 50.000 e 750.000 habitantes) foi significativamente elevada nas cidades que possuem um campus de IFET, a saber: Barbacena, Juiz de Fora, 
BARBOSA, A.M. et al. Cidades médias e atração de migrantes qualificados.

Governador Valadares, Montes Claros, Uberaba e Uberlândia. Esses municípios apresentaram índices positivos de TLM, exceto Governador Valadares, historicamente, marcado pela emigração internacional, como muitos estudos já demonstraram. ${ }^{4}$

Estudando a geografia dos fluxos migratórios, Rigotti (2006) investigou o comportamento dos migrantes de acordo com os níveis de escolaridade em Minas Gerais. Para tal, selecionou apenas os que possuíam, 25 anos ou mais de idade e os dividiu em dois grupos: o primeiro com 15 anos ou mais de estudo, ou seja, os mais escolarizados e o segundo grupo com indivíduos com até 4 anos de estudo, representava o segmento de pouca escolaridade. Entre 1986/1991, a pesquisa constatou que o Triângulo Mineiro recebeu migrantes qualificados da Região Metropolitana de Belo Horizonte, o que atesta o dinamismo da região receptora. Por outro lado, a constatação de migrantes qualificados do Norte do país em direção à Zona da Mata Mineira pareceu indicar um fluxo migratório de retorno, já que durante décadas houve fluxo migratório desta área para a região setentrional do Brasil.

O destaque para a instalação dos equipamentos educativos em localidades que não são metrópole ratifica a tese da desconcentração espacial seletiva de Matos (2005) no tocante à contribuição significativa da melhora das infraestruturas das cidades intermediárias para a densificação da rede urbana brasileira. A oportunidade trazida pelos IFETs de qualificação de força de trabalho para as demandas de mercados regionais, como constatado nas pesquisas de Souza (2010) e Tonial (2010), parece comprovar que essas instituições se tornam fator de atratividade, a

4 Cabe salientar que, além de Governador Valadares, somente Montes Claros ainda não possuía nenhuma instituição, por assim dizer, embrionária de IFET no período investigado. Curiosamente, Barbacena que sediava, até então, apenas uma escola agro-técnica federal apresentou a menor TLM, $1,85 \%$, sendo que a mais alta dos municípios citados foi de Uberlândia, com 14,19\%, sede de importante escola técnica de saúde, vinculada à Universidade Federal de Uberlândia, além de possuir uma escola agro-técnica federal. 
BARBOSA, A.M. et al. Cidades médias e atração de migrantes qualificados.

ponto de interferir na fixação da população migrante e não migrante, favorecendo aos seus egressos a inserção no mercado de trabalho local e microrregional.

Em detalhada investigação sobre cidades médias dinâmicas no Brasil, Matos (2009) levantou dados primários sobre os fatores de fixação nessas cidades, segundo opinião de seus habitantes, valendo-se de pesquisa de campo $^{5}$. O fator de fixação mais mencionado na investigação ("apego à família") foge ao arco investigativo desse artigo, contudo o destaque na pesquisa para o item "oportunidade de educação" reforça a ideia de que os equipamentos de educação em cidades intermediárias são fator de atratividade e fixação da população nessas localidades: atuam no processo de desconcentração demográfica dos grandes centros, à medida que possibilitam a qualificação profissional.

Entre os nove municípios mineiros pesquisados por Matos (2009), a saber, Barbacena, Juiz de Fora, Montes Claros, Pouso Alegre, São João Del Rei, Uberlândia, Alfenas, Sete Lagoas e Três Corações, apenas os três últimos não possuem sedes de IFETs $^{6}$. Ao que tudo indica, a presença do IFET em Minas Gerais se mostra bem mais impactante na atualidade, no que se refere ao número de unidades, vagas e cursos ofertados, do que o que se apresentava no período de 1986-1995, quando as escolas técnicas federais, voltadas para o setor industrial, eram apenas três em Minas Gerais. Neste período, Rigotti e Campos (2009) ao analisarem os saldos migratórios de 131 municípios de porte médio em Minas Gerais constataram que embora a metade deles tenha apresentado saldo

5 Mediante metodologia própria e filtros estatísticos e espaciais foram investigados fatores de natureza cultural, geocultural e socioeconômica.

${ }^{6}$ Porém, no que se refere ao ensino público, fazem parte do Programa de Educação Profissional (PEP), do Estado de Minas Gerais, com cursos técnicos de nível médio e, no caso de Alfenas, a cidade possui ainda uma Universidade Federal. 
BARBOSA, A.M. et al. Cidades médias e atração de migrantes qualificados.

migratório $^{7}$ positivo, no cômputo geral, houve, no estado, saldo negativo de 11 mil habitantes. Os achados da pesquisa de Rigotti e Campos (2009, p. 12), alertam que "não se pode generalizar a suposta capacidade das cidades médias em atrair população" e apontam Uberlândia e Juiz de Fora como os Centros Regionais mais dinâmicos do ponto de vista da atração populacional também no segundo quinquênio analisado, de 1995-2000. O destaque das duas cidades se repete no caso de movimentos pendulares envolvendo cidades de médio porte e demonstra que estas localidades recebem pessoas procedentes de cidades menores, ratifica o caráter regional das interações já que, quanto maior o volume destes fluxos, maior a participação do entorno imediato. Além disso, no quinquênio 1995-2000, os autores identificam novo dinamismo no estado em face do saldo migratório positivo de 18 mil habitantes, o que representa um ganho total de quase $30 \mathrm{mil}$ habitantes, em relação ao período anterior. A evidência de Juiz de Fora e Uberlândia encontrada no trabalho de Rigotti e Campos (2009) chama atenção também pelo fato de serem duas cidades que, historicamente, contam com a presença de escola técnica federal de ênfase industrial e agrícola, respectivamente.

A concentração de população, em quantidade e qualidade suficiente para o trabalho, é um importante fator de indução do crescimento econômico. Da mesma forma, o papel do Estado como definidor da localização dos Institutos Federais, parece ser fator decisivo na formação de novas economias de aglomeração. Se no início da ocupação do território brasileiro a centralidade esteve na disponibilidade e apropriação de recursos naturais, a expansão dos meios de transporte e comunicações diminuiu o papel dos ativos naturais e contribuiu para o surgimento de núcleos econômicos e demográficos ligados à qualificação e ao trabalho.

$7 \mathrm{O}$ verdadeiro conceito de saldo migratório resulta da diferença entre imigrantes e emigrantes de "data fixa" e mede a contribuição das migrações ao crescimento populacional do período (CARVALHO e RIGOTTI, 1998, p. 341). 
BARBOSA, A.M. et al. Cidades médias e atração de migrantes qualificados.

\section{(In)Flexão empírica em 2010: IFET e cidades médias dinâmicas}

Para explorar os dados do Censo de 2010, Barbosa (2013) selecionou as localidades intermediárias de Minas Gerais que possuíam entre 50 mil e 750 mil habitantes urbanos ${ }^{8}$ e não faziam parte da Área Metropolitana de Belo Horizonte. A adjetivação "dinâmica" foi conferida àquelas que sustentaram o crescimento demográfico e econômico na última década. Outro recurso metodológico adotado a fim de compreender o dinamismo desses municípios e a atratividade do setor produtivo foi o de recortar os imigrantes por nível de escolaridade e atividade produtiva na qual estava inserido.

$\mathrm{Da}$ análise dos dados foi possível deduzir que a presença do IFET no município, não deve ter alterado a tendência diferenciada no que tange a níveis superiores da taxa de crescimento da população urbana. Sua oscilação não parece sofrer influência do equipamento educacional entre os anos de 2000 e 2010. Contudo, a classificação advinda da conjugação das variações encontradas na Taxa de Crescimento Geométrico da População e na Taxa de Crescimento Geométrico da Renda Mediana da População Empregada permitiu constatar que quatro municípios servidos por

${ }^{8}$ Adota-se aqui os critérios metodológicos utilizados em Matos (2009 e 2013) e na pesquisa "Desigualdades Socioespaciais e Descentralização Territorial no Brasil Atual" desenvolvida no Laboratório de Estudos Territoriais do Departamento de Geografia da UFMG. Para filtrar os municípios dinâmicos intermediários com tamanho entre 50 e 750 mil habitantes, um critério mais importante que a definição desse intervalo foi o da seleção dos que mantiveram crescimento econômico do PIB e da população urbana continuadamente entre 2000 e 2010. Serve de exemplo Uberlândia e Juiz de Fora, dois municípios dinâmicos não integrantes da região metropolitana, que em 2010 tinham 604.013 e 516.247 habitantes respectivamente, tamanhos estes ainda distantes do "teto" de 750 mil habitantes. 
BARBOSA, A.M. et al. Cidades médias e atração de migrantes qualificados.

IFET se mostraram mais dinâmicos: Montes Claros, Paracatu, Uberaba e Uberlândia. ${ }^{9}$ (BARBOSA, 2013, p.152).

Evidentemente, é preciso lembrar que o Brasil já vive a realidade de declínio tendencial das taxas de crescimento há décadas, como resultado da queda da fecundidade e de um processo amplo de redistribuição da população no espaço. Assim, crescimento de populações acima da média nacional $(1,17 \%$ a.a) e estadual $(0,91 \%$ a.a), mesmo que possa ser aparentemente baixo, pode esconder significados que o analista deve considerar. Um desses significados diz respeito ao comportamento dos saldos migratórios, outro se associa às comparações com o crescimento da renda per capita.

Nesse sentido, a tese de Barbosa (2013) também destaca aspecto relevante ligado ao fato de as taxas de crescimento da renda per capita situarem-se em níveis muito superiores aos das taxas de crescimento demográfico, o que atesta o período virtuoso que o país vivenciava entre 2000 e 2010 em termos de redução dos níveis de pressão no mercado de trabalho. Fica evidente que boa parte desse dinamismo localiza-se nas cidades médias. Essas cidades, uma vez equipadas (com ou sem IFETs) polarizam boa parte do dinamismo da economia mineira. Entretanto, é plausível apostar na hipótese que estabelecimentos especializados de ensino contribuem para a desenvoltura dessas cidades e os dados sobre migração interna devem confirmar essa assertiva.

No que se refere à capacidade de atração de imigrantes, o que supõe existência de condições de fixação do habitante no município, entre 2000 e 2010 os saldos migratórios positivos indicam a presença de 31 municípios mineiros sem IFET, cujos

9 Uberlândia, Montes Claros e Uberaba (juntamente com Juiz de Fora) situam-se entre os oito maiores municípios de Minas Gerais pelo Censo de 2010 (Paracatu na $38^{\mathrm{a}}$ posição). Ocupam também as primeiras posições em termos de Produto Interno Bruto $\left(5^{\mathrm{a}}, 9^{\mathrm{a}}\right.$ e $12^{\mathrm{a}}$, respectivamente), só ultrapassados por municípios integrantes da Região Metropolitana de Belo Horizonte. Já o município de Paracatu, na série de valores de PIB de 2010, ocupa a $34^{\mathrm{a}}$ posição. 
BARBOSA, A.M. et al. Cidades médias e atração de migrantes qualificados.

saldos são inferiores aos dos 17 municípios médios que contam com essa instituição educacional. Diante dos comentários feitos anteriormente sobre o declínio do crescimento demográfico brasileiro, é de se esperar a redução dos saldos migratórios positivos em municípios receptores de migrantes, como revela o Censo de 2010. De fato, entre os municípios que contam com IFETs, os saldos migratórios positivos equivalem a $61 \%$ dos verificados no quinquênio anterior. Já entre os desprovidos desses equipamentos, os saldos positivos não ultrapassaram $36,8 \%$ do saldo migratório do quinquênio 1995/2000. ${ }^{10}$

\section{Conclusões}

Compreender as trajetórias migratórias recentes no país, controlando o nível de escolaridade e a inserção na atividade produtiva, certamente ajuda a deslindar a lógica que perpassa $o$ dinamismo de muitas localidades de porte médio. Se as cidades se mostram como espaço preferencial do desenvolvimento, posto que nelas incidem decisões de investimento e de localização da produção, pode-se afirmar que as cidades médias dinâmicas confirmam essa trajetória e suportam a recepção de instituições de ensino que, no Brasil recente ocorre principalmente pela difusão de Institutos Federais de Educação, Ciência e Tecnologia.

Os dados aqui mencionados validam a pertinácia desse tipo de equipamento, porquanto parecem imprimir no espaço geográfico, um fator adicional de coesão na rede de cidades por meio da presença de cidades médias com alta capacidade de atração de migrantes internos, desejosos de melhorar seu padrão de vida e inserção econômica. Enfim, trata-se de um novo elemento aglutinador de forças econômicas, simultaneamente atraídas e difusoras de inovação e dinamismo.

10 Paralelamente, nota-se que as externalidades positivas geradas pelos IFETs parecem impactar com mais vigor os municípios de menor porte, aqueles com população urbana em 2010, inferior a 100 mil habitantes. 
BARBOSA, A.M. et al. Cidades médias e atração de migrantes qualificados.

\section{Referências bibliográficas}

AMORIM FILHO, O.B; ABREU, J.F. Cidades médias e descentralização tecnológica: o caso de Minas Gerais. Caderno de Geografia, Belo Horizonte, v. 12, n. 18, p. 5-14, 2002.

AMORIM FILHO, O.B.; RIGOTTI, J.I.R. Os limiares demográficos na caracterização das cidades médias. In: ENCONTRO DA ASSOCIAÇÃO BRASILEIRA DE ESTUDOS POPULACIONAIS, 13., 2002, Ouro Preto. Anais... Ouro Preto: ABEP, 2002. p. 1-22.

BARBOSA, A.M. Educação, desenvolvimento e migração em cidades médias de Minas Gerais equipadas com Instituto Federal de Educação, Ciência e Tecnologia. 2013. 202 f. Tese. (Doutorado em Geografia)-Instituto de Geociências, Programa de Pós-Graduação em Geografia, Universidade Federal de Minas Gerais, 2013.

BASTOS, S.Q.A.; FREGUGLIA, R.S.; PROCÓPIO, I.V. Efeitos da mobilidade intermunicipal sobre a desigualdade de renda no Brasil: uma análise contrafactual. In: ENCONTRO NACIONAL DE ECONOMIA, 38, 2010, Salvador, Anais... Salvador, 2010. Disponível em: <www.anpec.org.br/ .../000d248c0b 1c1ac 5bb1 e8b53afb28997fee.doc>. Acesso em: 01 nov. 2011.

CARVALHO, J.A.M.; RIGOTTI, J.I.R. Os dados censitários brasileiros sobre migrações internas: algumas sugestões para análise. In: ENCONTRO NACIONAL DE ESTUDOS POPULACIONAIS DA ABEP, 11.,1998, Caxambu . Anais... Caxambu: ABEP, 1998. p.339-357.

CORREAA, R.L. Estudos sobre a rede urbana. Rio de Janeiro: Bertrand Brasil, 2006. 
BARBOSA, A.M. et al. Cidades médias e atração de migrantes qualificados.

Trajetórias geográficas. $2^{\mathrm{a}}$ edição. Rio de Janeiro: Bertrand Brasil, 2001.

DINIZ, C.C. Desenvolvimento poligonal no Brasil: nem desconcentração, nem contínua polarização. Nova Economia, v. 31, no 11, p.35-64, 1993.

GAULT M. Villes intermédiaires pour l'Europe. Paris: SyrosAlternatives, 1989. 220 p.

LOBO, C. Migrações e dispersão espacial da população brasileira. In: MATOS, R.; SOARES, W. (Orgs.) Desigualdades, redes e espacialidades emergentes no Brasil. Rio de Janeiro: Garamond, 2010. p. 115-136.

- Dispersão espacial da população nas regiões de influência das principais metrópoles brasileiras. 2009. $164 \mathrm{f}$. Tese. (Doutorado em Geografia)-Instituto de Geociências, Programa de Pós-Graduação em Geografia, Universidade Federal de Minas Gerais, 2009.

MARQUES DA COSTA, E. Cidades Médias: contributos para sua definição. Finisterra, Revista do Centro de Estudos Geográficos da Universidade de Lisboa, ano 28, n. 74, Lisboa, p. 101-128, 2002.

MARTINE, G. Ciclos e destinos da migração para áreas de fronteira na era moderna. Brasília: Instituto SPN. Documento de Trabalho, $\mathrm{n}^{\circ} 12,1992$.

MATOS, R. Percepção dos moradores e fatores de atração em cidades médias dinâmicas. Mercator, Fortaleza, v.12, n. 27, p. 39-55, jan/abr.2013

Desigualdades sócio-espaciais: inserções teóricas e conceituais e discussão do caso brasileiro. In: MATOS, R.; 
BARBOSA, A.M. et al. Cidades médias e atração de migrantes qualificados.

SOARES, W. (Orgs.) Desigualdades, redes e espacialidades emergentes no Brasil. Rio de Janeiro: Garamond, 2010. p. 19-59.

. Fatores de fixação em cidades intermediárias e percepção dos habitantes. In: ENCONTRO NACIONAL SOBRE MIGRAÇÕES, 6, 2009, Belo Horizonte. Anais ... Belo Horizonte: GT Migração da ABEP/CEDEPLAR/FACE/UFMG, 2009.

. (Org.). Espacialidades em rede: população urbanização e migração no Brasil contemporâneo. Belo Horizonte: C/Arte, 2005.

. Dinâmica migratória e desconcentração da população na macrorregião de Belo Horizonte. Tese. (Doutorado em Demografia)- Faculdade de Economia, Centro de Desenvolvimento e Planejamento Regional, Universidade Federal de Minas Gerais, Belo Horizonte, 1995.

. Questões teóricas acerca dos processos de concentração e desconcentração da população no espaço. Revista Brasileira de Estudos de População, São Paulo, p. 35-58, 1995 b.

. Fixes and Flows: Migration in Contemporary Brazil. In: ANNUAL MEETING, 98, 2002, Los Angeles. V.1. The Association of American Geographers, 2002b. p. 1-410.

MOTTA, D.M.; AJARA, C. Rede Urbana Brasileira: Hierarquia das cidades. Curso de Gestão Urbana e Municipal. Belo Horizonte: ESAF, WBI, IPEA, CEF, 1999.

PULIDO, N. El espacio urbano latinoamericano y la globalización. Emergencia de ciudades 'intermedias' y nuevos cambios en Venezuela. In: LEMOS, A.I.G.; ARROYO, M.; SILVEIRA, M.L. América Latina: ciudad, campo y turismo. Buenos Aires: CLACSO, São Paulo: USP, 2006. p. 149-171. 
BARBOSA, A.M. et al. Cidades médias e atração de migrantes qualificados.

. Les tendances récentes de l'urbanisation au Venezuela: le rôle des villes moyennes. Tesis de Doctorado presentada en la Universidad de Toulouse-Le Mirail, Francia. 1999.

RIGOTTI, J.I.R. Geografia dos fluxos populacionais segundo níveis de escolaridade dos migrantes. Estudos avançados 20 (57), 2006. p. 237-254.

RAMOS, E.F. Para onde vão as cidades médias? Uma análise a partir dos papéis e tendências de um grupo de cidades médias brasileiras. 2011. Dissertação (Mestrado em Geografia)- Instituto de Geociências, Universidade Federal de Minas Gerais, Belo Horizonte, 2011.

RIGOTTI, J.I.R.; CAMPOS, J. Movimentos populacionais e as cidades médias de Minas Gerais. In: Anais do VI Encontro Nacional sobre migrações. GT Migração ABEP. Belo Horizonte: CEDEPLAR/FACE/UFMG, 2009.

SANFELIU, C.B.; TORNÉ, J.M.L. Miradas a otros espacios urbanos: lãs ciudades intermédias. Geocrítica/Scripta Nova. Revista electrónica de geografia y ciências sociales. Barcelona: Universidad de Barcelona, v. 8, n. 165, 15 mai 2004. Disponível em: $<$ http://www.ub.es/geocrit/sn/sn-165.htm $>$. Acesso em $12 / 03 / 2011$.

SOUZA, S.C.L. A contribuição da Educação Profissional para a inserção dos alunos no mercado de trabalho da microrregião do extremo Sul catarinense: caso IFET campus Sombria. 2010. Dissertação (Mestrado em Educação)-Programa de Pós-Graduação em Educação, Universidade de Brasília, Brasília, 2010.

TONIAL, S.M. A trajetória profissional dos alunos egressos do IFET do Rio Grande do Sul: campus Sertão. 2010. Dissertação (Mestrado em Educação)-Programa de Pós-Graduação em Educação, Universidade Rural do Rio de Janeiro, Rio de Janeiro, 2010. 
BARBOSA, A.M. et al. Cidades médias e atração de migrantes qualificados.

Recebido em maio de 2015

Aceito em outubro de 2015

Geosul, v.30, n.60, 2015 